\title{
УПРАВЛЕНИЕ ДОХОДАМИ ГОСУДАРСТВЕННЫХ И МУНИЦИПАЛЬНЫХ МЕДИЦИНСКИХ ОРГАНИЗАЦИЙ
}

\author{
(C) 2019 Валиева Елизавета Николаевна \\ доктор экономических наук, профессор кафедры финансов и кредита \\ Самарский государственный экономический университет, Россия, Самара \\ E-mail: rad8063@yandex.ru
}

Целью осуществляемого в РФ реформирования финансов здравоохранения является обеспечение населения доступной и качественной медицинской помощью. Однако объемы финансирования медицинской помощи остаются недостаточными для бесплатного оказания гарантированных медицинских услуг. В этих условиях эффективность управления денежными средствами, поступающими в распоряжение медицинских организаций, является актуальной задачей менеджмента. Отечественная экономическая наука в последние годы уделяет внимание теории финансов некоммерческих, в том числе медицинских организаций (К.В. Екимова, М.В. Мельник, Г.Б. Поляк), вопросам внутреннего финансового контроля в учреждениях здравоохранения (И.А. Ануфриева, И.Ю. Гарнов, Т.Ф. Романова), а также планированию и оценке эффективности их деятельности (Ф.Н. Кадыров, Е.Г. Князева, М.М. Левкевич, О.В. Обухова, М.В. Пирогов, А. В. Решетников, И.М. Шейман). Вместе с тем, ощущается недостаток исследований, направленных на разработку конкретных инструментов управления денежными потоками медицинских организаций.

Объектом данного исследования выступают финансы государственных и муниципальных медицинских организаций, предметом - управление доходами медицинских организаций. Теоретико-методологическое значение работы заключается в обосновании элементов механизма управления финансовыми ресурсами медицинских организаций в системе «поступления, затраты, тарифы», а также анализе внешних факторов, влияющих на доходы учреждений здравоохранения.

Ключевые слова: доходы медицинских организаций, оплата медицинских услуг, динамика нормативов финансирования медицинской помощи.

Финансовыми ресурсами (располагаемыми доходами) государственных и муниципальных медицинских организаций (МО) является общая сумма денежных средств, поступающих им в процессе оказания медицинской помощи и некоторых других случаях (например, при реализации имущества). Текущее управление доходами МО в рамках разработанного менеджментом финансового механизма [5] предполагает их планирование, учет и анализ в пределах данного финансового года.

Процесс планирования поступления денежных средств в МО должен быть нацелен на достижение ее платежеспособности. При этом необходимо принимать во внимание имеющуюся систему оплаты медицинских услуг, которая действенным инструментом финансового управления не только на уровне организаций, но и в здравоохранении в целом. Данной проблематике посвящены публикации С.А. Банина [1], Л.С. Гринкевич [3], Ф.Н. Кадырова [4], О.В. Обуховой [6], М.В. Пирогова [7], В.Ю. Семенова [8], Т.М. Скляр [9].
Общепризнано, что система оплаты медицинских услуг должна быть направлена на:

- стимулирование повышения качества медицинской помощи при сокращении расходов;

- обеспечение возможности планирования доходов МО;

- мотивирование снижения управленческих расходов;

- обеспечение возможности перераспределение финансовых ресурсов в целях повышения результативности их использования.

В таблице 1 отражены способы оплаты медицинских услуг многопрофильной МО в разрезе источников финансирования и видов медицинской помощи.

Финансовое управление в МО предполагает учет особенностей оплаты медицинской помощи в процессе оперативного планировании доходов и направлений их использования. Планирование доходов медицинской организации следует осуществлять, учитывая источники финансирования медицинских услуг и их плановую стоимость или прейскурантную цену. 
Таблица 1. Оплата медицинских услуг в многопрофильной медицинской организации

\begin{tabular}{|c|c|c|}
\hline $\begin{array}{c}\text { Медицинская } \\
\text { услуга }\end{array}$ & Источник финансирования & Порядок оплаты \\
\hline $\begin{array}{l}\text { Амбулаторно- } \\
\text { поликлиническая } \\
\text { помощь }\end{array}$ & $\begin{array}{l}\text { Обязательное медицинское страхование } \\
\text { Региональный бюджет } \\
\text { Средства пациентов }\end{array}$ & $\begin{array}{l}\text { По подушевому нормативу; по тарифу за } \\
\text { медицинскую услугу } \\
\text { Субсидирование } \\
\text { По прейскуранту Мо }\end{array}$ \\
\hline $\begin{array}{l}\text { Стационарная } \\
\text { помощь }\end{array}$ & $\begin{array}{l}\text { Обязательное медицинское страхование } \\
\text { Региональный бюджет } \\
\text { Средства пациентов }\end{array}$ & $\begin{array}{l}\text { По тарифу за законченный случай лечения } \\
\text { Субсидирование } \\
\text { По прейскуранту МО }\end{array}$ \\
\hline $\begin{array}{l}\text { Стационарозаме- } \\
\text { щающая помощь }\end{array}$ & $\begin{array}{l}\text { Обязательное медицинское страхование } \\
\text { Средства пациентов }\end{array}$ & $\begin{array}{l}\text { По тарифу за законченный случай лечения } \\
\text { По прейскуранту МО }\end{array}$ \\
\hline Скорая помощь & Обязательное медицинское страхование & $\begin{array}{l}\text { По подушевому нормативу; по тарифу за } \\
\text { вызов } \\
\text { Субсидирование }\end{array}$ \\
\hline
\end{tabular}

В процессе исполнения финансового плана по доходам необходим контроль за динамикой показателей исполнения плана по структуре и объему оказываемой медицинской помощи, а также за исполнением сроков оплаты оказанных услуг.

Виды и объем услуг целесообразно планировать в разрезе способов оплаты медицинской помощи, финансируемых за счет данного источника. В соответствии с принципом оптимизации плановых решений возможно составление альтернативных вариантов планов доходов, основанных на альтернативной структуре доходных источников. Методика планирования доходов должна быть гибким инструментом, меняющимся в соответствии с внешними и внутренними параметрами хозяйствования.

Законодательством определены следующие источники финансирования МО:

- поступления из федерального бюджета, перераспределяемые через региональный бюджет;

- финансирование из регионального бюджета;

- средства ОМС;

- доходы от предпринимательской деятельности.

Поступления из бюджетной системы включают субсидии на выполнение государственного задания и целевые субсидии.

Следует подчеркнуть, что планируемые поступления от оказания медицинской услуги в случае ее оплаты за счет средств ОМС или средств пациентов принимаются равными цене услуги или тарифу, по которой она будет реали- зована. При бюджетном финансировании ситуация другая. Утверждаемая сумма субсидии никак не связана с совокупными затратами на общее количество оказываемых услуг. Получается, что чем больше оказано услуг, тем они дешевле. При увеличении объемов помощи услуга дешевеет, при сокращении - дорожает. Медицинская организация вынуждена ориентироваться не на качество услуги или эффективность затрат, а на снижение расходов.

Не располагая полномочиями влиять на цены на медицинские услуги, оказываемые по программе государственных гарантий, МО может регулировать фактические затраты по конкретному виду помощи. Анализ соотношения фактических затрат на услугу и плановой или средней стоимости услуги является актуальной задачей финансового управления в медицинских организациях. Финансовый менеджмент в рамках предпринимательской деятельности должен быть нацелен на оптимизацию структуры услуг, ценообразования и системы инкассации денежных поступлений. Практику управление только в связи с перераспределением предпринимательских доходов на недофинансируемые из бюджета и системы ОМС медицинские услуги необходимо преодолеть.

Группировку и анализ доходов необходимо осуществлять отдельно по фактическим и кассовым доходам. К фактическим доходам относятся причитающиеся денежные средства за оказанные медицинские услуги (выставленные счета страховым компаниям), но не поступившие на отчетную дату. Кассовыми доходами принято 
считать деньги, поступившие на текущий счет или в кассу. Финансовый менеджмент кассовых и фактических доходами предполагает использование различных инструментов. При формировании фактических доходов необходимо учитывать степень выполнения плана оказания услуг, их состав, стоимость. В процессе управления кассовыми доходами необходимо обращать внимание на порядок оплаты оказанных услуг, который различается в зависимости от вида медицинской помощи и источника финансирования.

Управление доходами должно учитывать меняющиеся внешние по отношению к МО факторы. Так, произошли изменения в практике планирования стоимости медицинских услуг и определения нормативов затрат на оказание услуг в Тарифном соглашении. От практики установления средних затрат на услугу в денежном выражении перешли к практике закрепления общей структуры расходов на ее оказание. Это позволяет манипулировать всеми видами затрат: на оплату труда, на медикаменты, на питание пациентов и др. Кроме того наблюдается тенденция сокращения количественных нормативов оказания дорогостоящих видов медицинской помощи, прежде всего стационарной.

К настоящему времени осуществлен переход к финансированию госзадания по единым нормативам затрат на медицинские услуги в соответствующем регионе. Финансирование МО осуществляется по нормативу, который должен быть не ниже среднего показателя по региону.
Объем средств на финансовое обеспечение гарантированных населению медицинских услуг в этом случае определяется следующими факторами: базовыми нормативами финансирования и корректирующими коэффициентами в разрезе видов услуг, объемами услуги по госзаданию, затратами на содержание имущества MO, и др. Таким образом, затратный подход финансирования медицинских услуг заменен на финансирование по нормативной стоимости. В этих условиях МО получают больше рычагов для управления доходами и финансовой эффективностью основной деятельностью.

Обеспеченность финансовыми ресурсами МО зависит не только от обоснованности их финансовых планов, но и от утвержденных объемов бюджетных ассигнований на здравоохранение и стоимости территориальной программы обязательного медицинского страхования в регионе. Последний показатель особенно важен, так как поступление финансовых ресурсов в многопрофильные МO на восемьдесят процентов осуществляется по линии ОМС. Анализ динамики нормативов финансирования медицинских услуг в Самарской области на основе постановлений Правительства Самарской области за 20142018 гг. «Об утверждении территориальной программы государственных гарантий бесплатного оказания населению Самарской области медицинской помощи» представлен в таблице 2.

За анализируемый период изменение норматива финансирования территориальной программы характеризовалось разнонаправленной

Таблица 2. Анализ изменения нормативов финансирования медицинской помощи в Самарской области $(2015$ г. -2019 г.) *

\begin{tabular}{|c|c|c|c|c|c|c|c|c|c|}
\hline \multirow[b]{2}{*}{$\begin{array}{c}\text { Нормативы финансирова- } \\
\text { ния }\end{array}$} & \multirow[b]{2}{*}{$\begin{array}{c}2015 \\
\text { год } \\
\text { (руб.) }\end{array}$} & \multicolumn{2}{|c|}{2016 год } & \multicolumn{2}{|c|}{2017 год } & \multicolumn{2}{|c|}{2018 год } & \multicolumn{2}{|c|}{2019 год } \\
\hline & & Руб. & $\begin{array}{l}\text { Темп } \\
\text { роста } \\
(\%)\end{array}$ & Руб. & $\begin{array}{c}\text { Темп } \\
\text { роста } \\
(\%)\end{array}$ & Руб. & $\begin{array}{c}\text { Темп } \\
\text { роста } \\
(\%)\end{array}$ & Руб. & $\begin{array}{c}\text { Темп } \\
\text { роста } \\
(\%)\end{array}$ \\
\hline $\begin{array}{l}\text { Посещение поликлиники в } \\
\text { связи с лечением } \\
\text { - из областного бюджета } \\
\text { - по ОМС }\end{array}$ & $\begin{array}{l}1050 \\
1014\end{array}$ & $\begin{array}{c}1065 \\
950\end{array}$ & $\begin{array}{c}101,4 \\
93,7\end{array}$ & $\begin{array}{c}1052 \\
946\end{array}$ & $\begin{array}{l}98,8 \\
99,6\end{array}$ & $\begin{array}{l}1047 \\
1090\end{array}$ & $\begin{array}{c}99,5 \\
115,2\end{array}$ & $\begin{array}{l}1052 \\
1083\end{array}$ & $\begin{array}{c}100,5 \\
99,3\end{array}$ \\
\hline $\begin{array}{l}\text { Один случай лечения в } \\
\text { дневном стационаре } \\
- \text { из областного бюджета } \\
- \text { по ОМС }\end{array}$ & $\begin{array}{c}400 \\
1324\end{array}$ & $\begin{array}{l}10868 \\
10803\end{array}$ & $\begin{array}{c}27 \text { раз } \\
816\end{array}$ & $\begin{array}{l}10733 \\
10698\end{array}$ & $\begin{array}{l}98,8 \\
99,0\end{array}$ & $\begin{array}{l}10697 \\
12570\end{array}$ & $\begin{array}{c}99,7 \\
117,5\end{array}$ & $\begin{array}{l}10743 \\
15860\end{array}$ & $\begin{array}{l}100,4 \\
126,2\end{array}$ \\
\hline $\begin{array}{l}\text { Один случай лечения в } \\
\text { условиях стационара } \\
\text { - из областного бюджета } \\
\text { - по ОМС }\end{array}$ & $\begin{array}{l}60380 \\
22651\end{array}$ & $\begin{array}{l}63244 \\
22177\end{array}$ & $\begin{array}{c}104,7 \\
97,9\end{array}$ & $\begin{array}{l}62182 \\
21788\end{array}$ & $\begin{array}{l}98,3 \\
98,2\end{array}$ & $\begin{array}{l}61973 \\
25717\end{array}$ & $\begin{array}{c}99,7 \\
118,0\end{array}$ & $\begin{array}{l}62226 \\
26421\end{array}$ & $\begin{array}{l}100,4 \\
102,7\end{array}$ \\
\hline $\begin{array}{l}\text { Среднедушевой норматив } \\
\text { финансирования террито- } \\
\text { риальной программы ОМС }\end{array}$ & 8502 & 8128 & 95,6 & 8132 & 100,0 & 9348 & 115,0 & 9768 & 104.5 \\
\hline
\end{tabular}

* Абсолютные показатели пересчитаны в цены 2015 г. по индексу-дефлятору ВВП 
динамикой. В 2019 году его рост по сравнению с базовым периодом составил 15\%. Финансирование поликлинической помощи осталось на уровне 2015 года. Такая же картина наблюдается и в части финансирования дневных стационаров за счет средств областного бюджета, темп рост соответствующих поступлений за счет ОМС с 2016 года равен 147\%. Финансирование стационарной помощи растет только за счет страховых средств (на 17\%). Нормативы финансирования лечения в условиях стационара за счет средств областного бюджета в 2019 году осталось на уровне 2015 года. В целом можно говорить о наметившейся положительной тенденции в финансовом обеспечении здравоохранения в регионе.

Дефицит финансовых ресурсов в системе ОМС объясняется методическим подходом к определению подушевых нормативов финансирования [10]. Фактические затраты как непосредственно связанных с оказанием медицинской помощи, так и необходимые для обеспечения деятельности медицинской организации учитываются только при расчете коэффициентов дифференциации затрат по половозрастным группам. Среднедушевой норматив финансирования страховых медицинских организаций (определяющий компонент формулы) зависит в первую очередь от «поступивших в отчетном месяце в бюджет территориального фонда средств на финансовое обеспечение обязательного медицинского страхования (без учета остатка средств за предыдущие периоды)». По сути - это разновидность остаточного принципа финансирования.

Тарифы на оплату медицинских услуг поликлиник рассчитываются «на основе подушевого норматива финансирования медицинской организации, исходя из данных об объеме средств в соответствии с установленной долей средств для подушевого финансирования амбулаторной медицинской помощи и численности прикрепленных к медицинской организации застрахованных лиц. При определении доли средств подушевого финансирования учитывается соотношение объема медицинской помощи, включенного в подушевой норматив, к общему объему оказанной медицинской помощи.» [10]. (Сохранены стиль и орфография источника.)

Таким образом, тарифы на оплату медицинских услуг тоже зависят от поступивших на ОМС финансовых ресурсов, прежде всего, страховых взносов. По нашим оценкам недофинансирование (разница между понесенными затратами и поступившей оплатой) в процентах к фактическим затратам в среднем в многопрофильной медицинской организации составляет $6 \%$, а по амбулаторно-поликлинической помощи - $13 \%$. Некоторое представление о величине и динамике тарифов на оплату поликлинической помощи позволяет получить таблица 3.

Абсолютную величину тарифов на амбулаторно-поликлинические услуги сложно оценить с качественной стороны. Можно попытаться охарактеризовать ее с точки зрения доли в тарифе оплаты труда, которую принято устанавли-

Таблица 3. Выборочный анализ динамики тарифов на амбулаторно-поликлинические услуги в системе ОМС Самарской области *

\begin{tabular}{|c|c|c|c|c|c|c|c|c|c|}
\hline \multirow[b]{2}{*}{ Медицинская услуга } & \multirow{2}{*}{$\begin{array}{c}2015 \\
\text { год } \\
\text { тариф } \\
\text { (руб.) }\end{array}$} & \multicolumn{2}{|c|}{2016 год } & \multicolumn{2}{|c|}{2017 год } & \multicolumn{2}{|c|}{2018 год } & \multicolumn{2}{|c|}{2019 год } \\
\hline & & $\begin{array}{c}\text { Тариф } \\
\text { (руб.) }\end{array}$ & $\begin{array}{c}\text { Темп } \\
\text { роста } \\
(\%)\end{array}$ & $\begin{array}{l}\text { Тариф } \\
\text { (руб.) }\end{array}$ & $\begin{array}{c}\text { Темп } \\
\text { роста } \\
(\%)\end{array}$ & $\begin{array}{l}\text { Тариф } \\
\text { (руб.) }\end{array}$ & $\begin{array}{c}\text { Темп } \\
\text { роста } \\
(\%)\end{array}$ & $\begin{array}{l}\text { Тариф } \\
\text { (руб.) }\end{array}$ & $\begin{array}{c}\text { Темп } \\
\text { роста } \\
(\%)\end{array}$ \\
\hline $\begin{array}{l}\text { Терапевта (прием и } \\
\text { консультация) }\end{array}$ & 237,49 & 224,47 & 94,5 & 213,17 & 95,0 & 245,03 & 114,9 & 234,69 & 95,8 \\
\hline $\begin{array}{l}\text { Оториноларинголога } \\
\text { (прием и консультация) }\end{array}$ & 182,31 & 172,32 & 94,5 & 163,64 & 95,0 & 188,08 & 114,9 & 180,15 & 95,8 \\
\hline $\begin{array}{l}\text { Кардиолога (прием и } \\
\text { консультация) }\end{array}$ & 271,73 & 256,83 & 94,5 & 243,9 & 95,0 & 280,35 & 114,9 & 268,52 & 95,8 \\
\hline $\begin{array}{l}\text { Онколога (прием и кон- } \\
\text { сультация) }\end{array}$ & 272,21 & 257,29 & 94,5 & 244,33 & 95,0 & 280,84 & 114,9 & 281,11 & 100,1 \\
\hline $\begin{array}{l}\text { Неотложная помощь на } \\
\text { дому (вызов) }\end{array}$ & 453,31 & 428,5 & 94,5 & 530,42 & 123,8 & 609,68 & 114,9 & 604,41 & 99,1 \\
\hline $\begin{array}{l}\text { Терапевта на дому (по- } \\
\text { сещение) }\end{array}$ & 168,41 & 158,92 & 94,4 & 151,16 & 95,1 & 173,75 & 114,9 & 166,42 & 95,8 \\
\hline
\end{tabular}

* Рассчитано по Приложению № 1 к Тарифному соглашению в системе обязательного медицинского страхования Самарской области

**** Абсолютные показатели пересчитаны в цены 2015 г. по индексу-дефлятору ВВП 
вать на уровне 50\%. Следовательно, зарплата за терапевтическую услугу (прием и консультация) составляет в 2019 году в Самарской области 140 рублей, что приблизительно соответствует 280 рублям в час, если отвести на медицинскую услугу 30 минут. Это на 37\% больше, чем среднечасовая зарплата в регионе при сорокачасовой рабочей неделе (204 руб.), а не в два раза, как этого требует указ президента. Однако, если исходить из фактически установленного времени на обслуживание пациента (15 минут), то указ даже перевыполнен. Напрашивается риторический вопрос: не приведет ли высокая производительность труда в здравоохранении к экономическому росту за счет знаменателя формулы его оценки?

Остановимся на динамике тарифов. Правила ОМС предусматривают пересмотр тарифов на медицинские услуги не реже, чем через три года. Увеличение тарифов на терапевтические услуги в 2018 году объясняется их плановым пересчетом. Однако, инфляция нивелировала их рост уже в следующем году. В целом за последние 5 лет тарифы снизились на $1,1 \%$, за исключением тарифа на услуги онколога, рост которого составил 3,3\%. Таким образом, динамика тарифов соответствует характеру изменения подушевых нормативов финансирования медицинской помощи.

При отсутствии реального роста финансирования здравоохранения из бюджетной системы обеспечение сбалансированности доходов и расходов медицинских организаций возможно за счет либо роста цен на медицинские услуги, оказываемые на платной основе либо роста количества этих услуг. Данный резерв ограничен платежеспособным спросом населения. По данным Росстата не смотря на рост зарплаты (около 1\%), «Индекс потребительской уверенности, отражающий совокупные потребительские ожидания населения, в IV квартале 2018 г. по сравнению с III кварталом 2018 г. снизился на 3 процентных пункта и составил (-17\%).» [11]. Эксперты прогнозируют, что в 2019 г. реальные доходы населения будут характеризоваться отрицательной динамикой [2]. В этих условиях особую значимость приобретает управленческий фактор: мониторинг фактических доходов в разрезе видов медицинской помощи по данным управленческого учета и регулирование структуры видов оказываемой медицинской помощи.

\section{Библиографический список}

1. Банин, С.А. Здравоохранение России: вопросы финансирования и пути решения [Текст] / С.А. Банин // Вестник Томского государственного университета. Экономика. - 2012.- № 3.- С. 112-117.

2. Белоусов Д., Климанов В., Широв А. Время скептиков / Журнал Эксперт № 1-3 (1103) 24 декабря 2018 / / www. expert.ru

3. Гринкевич, Л.С. Концептуальная модель формирования социально-ориентированной региональной системы финансирования медицинских организаций [Текст] /Л.С. Гринкевич, С.А. Банин// Финансы и кредит.2011.- № 36. - С. 35-47.

4. Кадыров, Ф.Н. Платные услуги в здравоохранении [Текст] / под ред. акад. РАМН В.И. Стародубова.-Москва: ИД Менеджер здравоохранения, 2013.- 220 с.

5. Курнакина, Н.В. Финансовый механизм медицинских организаций в РФ [Текст] / Н.В. Курнакина // Вестник Самарского государственного экономического университета. - 2014. - № 11.- С. 119-124

6. Обухова, О.В. Эффективные способы оплаты медицинской помощи в свете программы государственных гарантий [Текст] / О.В. Обухова, Ф.Н. Кадыров //Менеджмент в здравоохранении.- 2013. - № 11._- С. 6-13.

7. Пирогов, М.В. Особенности подушевого финансирования амбулаторной медицинской помощи [Текст] / М.В. Пирогов //Здравоохранение. - 2014.- № 4.- С. 20-25.

8. Семенов, В.Ю. Экономика здравоохранения [Текст]: учеб. пособие / В.Ю. Семенов.- Москва: Медицинское информационное агентство, 2006. - 472 с.

9. Скляр, Т.М. Роль медико-экономических стандартов в финансировании учреждений здравоохранения [Текст] / Т. М. Скляр // Вопросы экономики. - 2010. - № 8.- С. 46-51.

10. Приказ Министерства здравоохранения и социального развития. Российской Федерации от 28 февраля 2011 г. № 158н «Об утверждении правил обязательного медицинского страхования»

11. www. gks.ru 